\title{
The influence of digital platforms and algorithms on legal regulation of competition
}

\author{
Marina Kozlova ${ }^{*}$, Dmitriy Kozhemyakin ${ }^{2}$, Olga Sergacheva $^{3}$, and Alexandr Bortenev $^{4}$ \\ ${ }^{1}$ Volgograd Institute of Management, The Russian Presidential Academy of National Economy and State Administration, ul. Gagarina,8, \\ Volgograd, Russia, ORCID 0000-0002-6651-4392, kozlova-my@ranepa.ru \\ 2 Tomsk State University, 36, Lenin Avenue, Tomsk, Russia, ORCID 0000-0002-9722-4136, dv-k@outlook.com \\ ${ }^{3}$ Volgograd Institute of Management, The Russian Presidential Academy of National Economy and State Administration, ul. Gagarina,8, \\ Volgograd, Russia, ORCID: 0000-0002-7419-3277 sergacheva-oa@ranepa.ru \\ ${ }^{4}$ Volgograd Institute of Management, The Russian Presidential Academy of National Economy and State Administration, ul. Gagarina,8, \\ Volgograd, Russia, ORCID: 0000-0002-0239-554X bortenev-ai@ranepa.ru
}

\begin{abstract}
The antitrust regulation faces challenges in the context of digitalization and algorithmization; several of them are analyzed in the article. The authors explore the influence of digital platforms and pricing algorithms on competitive environment, the practice of their application in view of monopolizing the market and the possibilities to resist such practice from the point of view of the antitrust legislation. They examine the approaches to regulating digital instruments of pricing in order to ensure fair competition. One of the approaches is based on the fact that there is no need to develop specific regulatory instruments due to the lack of information on the consequences of algorithmic pricing applied to competition. Another one implies checking every new pricing algorithm in order to establish its influence on competitive environment and allowing or prohibiting it based on that. The third approach suggests further control using new legal standards that differ from the current ones. Banning algorithmic pricing is viewed as unreasonable as the pricing itself becomes more economically effective. The question of responsibility is raised for the cases when cartels are formed as a result of the activity of computer software. It is concluded that the owners of the software must be held accountable for any actions of the algorithm, as no program can act of its free will, they are controlled by the creator or the right holder.
\end{abstract}

\section{Introduction}

The changes in the structure of markets, the emergence of new business models under the influence of the digitalization and algorithmization processes lead to the necessity to ensure and protect competition on digital markets that have several specific features compared to the traditional ones.

For instance, the defining factor in this sphere is building a market around the competition of digital platforms that form the infrastructure for providing services and selling goods. The peculiarity of the way digital platforms function is the application of algorithms in order to process big volumes of data accumulated there in order to coordinate the activities of the platform's users, regulate their behavior, form a pricing policy.

Currently application of the business model based on digital platforms goes beyond providing services and selling goods on the Internet, as it recently was. Traditional offline services such as passenger and freight transport can also be managed based on platform decisions and algorithm application. In this case the Internet does not act as the environment for providing services like it does in case of digital content but rather as a necessary technological element of the platform's functioning.

Thus, the platform decisions and the technologies of algorithmization applied by them are spreading outside digital markets influencing the competition on the traditional ones. The application of business project algorithmization creates new possibilities for coordination of the activity of entities, and also new ways for monopolization. Organization for Economic Co-operation and Development [1] notes that one of the key challenges for competition policy connected to spreading digital data is using digital algorithms (formalized computer procedures) and establishing cartels using them.

\section{Problem Statement}

The development of economic relations, their digitalization and algorithmization lead to the emergence of new ways of doing business and to the development of smart technologies and gadgets. Using new technologies and business models (e.g. services for sharing resources such as houses, cars), creates previously unknown possibilities of collecting and

* Corresponding author: kozlova-my@ranepa.ru 
processing data about consumers, algoritmization (pricing algorithms, risk evaluation and prediction algorithms) is beneficial for the market participants; however, it is a challenge for the legislator. Law is unable to regulate these relations with traditional methods, they are intended for a different economical reality.

The questions related to digitalization and algorithmization as challenges to antitrust regulation are being discussed in the legal and economic literature. The issue of antitrust regulation in the digital epoch is undergoing integrated monographic research [2]; specific aspects of digitalization and its influence on competition legislation in particular countries are being studied as well [3].

The possibilities of using big data are analyzed; in this context probable competition issues are detected, as well as their potential influence on the performance of instruments of competition assistance and on the main spheres of work of the competition authorities [4].

The questions of the influence of computer technologies on competition environment are studied [5], as well as the possible application of the EU law on competition on digital markets [6].

The issues of influence of algorithmic pricing on the antitrust policy [7], of expansion of the term "collusion" considering the possibilities of computer technologies [8] are indicated.

However, there is no common understanding of how the competition authorities should respond to the challenges of the modern digital economy, whether they should use traditional instruments or develop new specific methods.

\section{Research Questions}

The research analyzes the practice of applying digital platforms and algorithms for monopolizing the market and to form approaches of the legislation to resist negative influence of such practice.

\section{Purpose of the Study}

The research is aimed at identifying the optimal approach for the competition authorities to react to the challenges of the digital age, such as using digital platforms and algorithms.

\section{Research Methods}

The methodology is based on general cognition methods: dialectical and systemic. Not only the general scientific methods of analysis, synthesis, induction and deduction were applied in the research, but also specific legal ones, the comparative legal method in particular.

\section{Findings}

The issue of digital platforms in competition practice is widely known and well-studied. It is based on the effect of the right holder of the platform controlling the goods and services market that appears due to the fact that the digital platform is the entrance point to the markets for both consumers and suppliers. Since the platform itself is a communicative service that lets a consumer find a supplier and vice versa, the platform's right holder controls not only the market of their own services but also all other markets where communication between contractors is conducted through using the platform [9].

Undoubtedly, control of this kind only becomes attainable in absence of sufficient amount of competing platforms and when the vast majority of consumers and suppliers concentrate around the monopolist platform. However, this exact situation can be seen at most digital markets.

Two factors lead to the emergence of monopolistic platforms. The first one is connected to the fact that developing, introducing and promoting digital platforms requires a lot of economical and organizational resources that new technological companies generally do not have, while technological giants do. Thus, the emergence of a lot of competing digital platforms is impeded by the high price of entering the market of the services provided. The situation is exacerbated by the fact that a lot of services provided by the platform right-holder are free, which excludes the possibility of rapid payback of investments.

The second factor impeding the emergence of a big amount of platforms are so-called network effects. Being a communicative service providing the connection of contractors at the market, digital platforms acquire value and significance only in case they have a lot of users. However, the more users the platform has, the more valuable it becomes for the more new users it attracts. It is understandable that the participants of the market that have a loyal audience that uses their other products are more likely to enjoy the advantages of the network than new market participants.

The network effect also intensifies due to circumstances preventing the clients from leaving the platform. The obstacles are connected to the fact that the clients get used to certain interfaces and possibilities and, consequently, they do not want to study new instruments provided by rival platforms.

Thus, the emergence and dominance of a limited amount of digital platform $\mathrm{s}$ can be considered a natural consequence of the process of their development and functioning.

However, the naturalness of the limited number of platforms does not mean that the competition authorities are to stop controlling the competition of such platforms with each other and their influence on related markets. For instance, the dominance of a digital platform can lead to the introduction of unreasonably high fees for using the platform for suppliers of services and goods. High fees on digital platforms along with the platform's price regulation can lead to decline in quality or safety of services, deterioration of working conditions in certain sectors of economy as it did in the taxi services market. 
The market influence of digital platforms can also lead to takeovers and displacement of independent suppliers and to establishing discriminating conditions for using the platform. Providing suppliers with the instrument of selling and providing services the platform owners can start competing with suppliers using the platform directly, driving them out of the market after gathering enough data.

In August 2020 the Federal Antimonopoly servic e of Russia has examined the case upon the complaint by "Kaspersky Lab" on Apple Inc. connected to abusing the dominant position on the market of mobile devices functioning on iOS. Apple Inc. has forced Kaspersky to significantly reduce the functionality of their parent control application in order to promote its own similar (competing) application "Screen time". The Federal Antimonopoly Service committee has admitted it to be abuse of dominant position in sense of part 1 of article 10 of the Federal law "On protection of competition" the actions of Apple Inc. on setting conditions for the developers of B2C applications to access App Store; they let the right holder decline or not admit any app of any developer for any reason. The actions of Apple of normative and behavioral character were also considered abuse of dominating position, and they have led to a considerable decline in functionality of parental control applications [10].

One of the effective instruments of maintenance of competition environment in digital markets is preventing the digital platforms from merging; it is performed via preliminary checks of merges takeovers [11].

One of the examples of successful application of this instrument is the refusal of the Federal Antimonopoly service to approve the agreement of joint action between groups of companies owning "Yandex. Taxi" and "Vezyot" taxi aggregators [12]. As it was concluded after the analysis conducted by the Antimonopoly service, in case the deal is settled, the market share will increase up to $70 \%$ within the borders of the Russian Federation, more than $80 \%$ within 19 regions of the Russian Federation and more than $50 \%$ within 32 regions of the Russian Federation.

However, the examples listed above of a successful response of the antimonopoly service and of prevention of monopolization of the market using digital platforms are more of an exception than a rule.

For instance, Tim $\mathrm{Wu}$ states that the antitrust legislation per se is not suitable for regulating the information industry, as its application is limited by cases of price manipulation and other specifically listed kinds of violations that do not necessarily characterize the activity of companies owning digital platforms [13].

A. Dotsenko and A. Ivanov note that economic concentration and the market power strengthening of digital platforms is mainly connected to collecting and concentration of a lot of data about the users. However, traditional antitrust regulation approaches do not regard such information as an asset and mainly focus on prices, which becomes pointless considering the fact that a lot of services are free on the platforms [9].

Application of algorithms for collecting and analyzing data can be used not only for the creation of digital platforms and monopolization of digital markets through them, but also for the coordination of activity of entities both in traditional and digital markets. For instance, algorithmization can be used for the elucidation of the price level and detection of demand. This process facilitates collusions and forming of cartels. There is problem of detection and of establishing responsibility for using algorithms for competition authorities.

An "algorithm" can be defined as a way (a program) of solving calculation and other tasks, exactly prescribing how to and in what sequence achieve a result clearly defined by the source data [14]. This term is used in different sciences, and has received a special meaning for business processes and relationships on competition protection. Price algorithm is a software product used to determine prices on goods using which estimation and (or) determination and (or) monitoring of prices are executed based on the parameters set by the algorithm's user.

Recent researches focus on the necessity of full analysis of pricing mechanisms in the digital age, as the sphere is of pronounced interdisciplinary character (economics, law, informatics, deontological ethics, etc.)

In a brief description of the pricing phenomenon and the behavior of entities in goods markets caused by it generally three types of pricing are distinguished in the literature [15]:

1.Dynamic pricing that happens in real time, a reaction on the situation in the market with undefined demand;

2.Personalized pricing that is also called price discrimination of the first degree, the price varies depending on the consumer's personality;

3. Algorithmic pricing is a result of rapid digitalization that has the features of both dynamic and personalized pricing; it's main characteristic is the fact that it is based on algorithms as key components of digitalization.

The consequences of application of mechanisms of algorithmic pricing by the entities present the most interest in this research.

A lot of companies use the potential of algorithmization in their businesses based on the analysis of a lot of data. Pricing algorithms dominate online selling of goods for optimization of the price based on the supply available and demand; they are also used for booking hotels and travels, in commerce, sports and entertainment [5].

A business based on algorithms includes predictions of demand, price changes, behavior and other preferences of clients, risk assessment and assumptions on upheavals that can influence the market environment. What is more, prediction can be used to optimize the decision taking process, development of new services.

Moreover, algorithms can be used to optimize business processes through the reduction of expenses, segmentation of consumers, setting optimal prices [16].

Using algorithms gives an undoubted competitive advantage in business; however, it can limit competition.

As it is noted in the literature, decisions about the prices are mostly handed to algorithms. Scientists and competition authorities express concerns about the fact 
that these algorithms can more effectively lead to collusions than people making decisions [7].

One of the first cases where a price-fixing cartel using algorithms was discovered was the one investigated by the United States Department of Justice about a collusion on prices on posters sold via the Amazon Marketplace. Participants of the cartel have agreed upon prices on particular posters; specific software was used to set prices according to the agreement [17]. However, there are examples of using algorithms for collusion in the "pre-digital" age; for example, the case of leading airlines of the USA agreeing on ticket tariffs using the database of the Airline Tariff Publishing Company. The case was not tried in court, the Department of Justice and the airlines have entered a settlement agreement [18]. It is emphasized that the influence of pricing algorithms is estimated differently in the literature. There are two groups of views: the most positive one states that the influence of pricing algorithms is exaggerated and the human factor influences most cartels more. The others say that the anti-competition potential of pricing algorithms is not fully realized yet; it will be realized as the algorithms are still at an early stage of development and the antimonopoly authorities are not yet capable to counteract misuse of digital instruments of this kind since it does not possess the necessary technical equipment [7].

American researchers Ezrachi and Stuke distinguish four main categories of cartels that are possible with the help of the algorithms - Messenger, Hub and Spoke, Predictable Agent and Digital Eye [5].

The first category of cartel agreements is based on the application of messengers. A cartel agreement is achieved and the data analysis carried out by software is used for creating, monitoring and controlling the cartel. A traditional collusion model is applicable to such agreements.

Competitors may agree on information exchange on prices and on application of a specific behavior model; for instance, setting a specific price, applying discounts etc. An algorithm can control the enforcement of the agreement. Limiting competition happens when the participants of the agreement cannot set their own prices.

The practice of the Federal Antimonopoly Service of the Russian Federation can serve as an example. For instance, a company that was the only one importing and selling LG smartphones on the territory of the Russian Federation, set the recommended retail prices on smartphones and then controlled if the retailers followed the guidelines. A special price algorithm was applied. When a deviation from the recommended prices was detected, the company put pressure on resellers applying sanctions (shipment termination) [19]. The company was found guilty in concluding anti-competition agreement, administrative measures were taken.

The second category of illegal agreements is based on using one algorithm for determining the market price by several subjects. One vertical agreement does not necessarily have an anti-competition effect; however, several vertical agreements with several subjects can lead to the creation of a classic branched cartel that leads to an increase in prices.

The third category (predictable agent) implies that on a complex market a situation can occur when different subjects use their own algorithms programming them in a certain way to react to changes in market situation. In this case the introduction of similar algorithms into the whole sphere can lead to an anti-competition effect due to the creation of interdependent actions. In order to facilitate the usage of price mechanisms the firms increase transparency which makes the market more sensitive to collusions due to which prices start growing. Importantly, the price increase is not a result of an explicit collusion, it is rather a natural consequence of a tacit collusion.

Conscious parallelism occurs when an algorithm of one entity interacts with other algorithms; for instance, under certain conditions competition ceases.

Using an algorithm one can also watch the prices of other entities not only for objective analysis but for coordination as well.

Using auction bots in e-tendering can lead to the establishment of such cartels.

The fourth category called Digital Eye implies that the competitors unilaterally create and use computer algorithms for achieving the set goal; for example, profit maximization.

The fact of using price algorithms in activities of entities is not viewed as violation of competition law, since it is actually a trade instrument. However, illegal coordination can be performed using the algorithms, or they can lead to cartel agreements.

There are other repercussions for the development of competition applying mechanisms of algorithmic pricing.

Calvano, Calzolari, Denicolo and Pastorello emphasize that using algorithmic pricing significantly expands the possibilities for price discrimination. Even though direct influence of price discrimination is generally not apparent, the prices set under the influence of pricing algorithms can depend not only from relatively "innocent" information such as the time of purchase or the remaining capacity of the firm, but also the complete purchase history of the buyer. Such pricing "under condition" can lead to so-called "poaching" of consumers or to using exclusivity or discount in order to get a share of the market, both of these consequences can have an anti-competition effect [7].

Currently the spread and development of digital platforms and the application of technologies of data processing outside exclusively digital markets compel to review traditional approaches to regulating competition.

For instance, the usual markers of market power abuse such as setting monopoly high or low prices can be ineffective in regard to the assessment of digital platforms, the expansion of market power of which is connected to the concentration of a lot of user data and the network effect connected to it.

Speaking of the phenomenon of algorithmic pricing and its influence on the state of competition, three main approaches are to be noted; they concern how the 
application of digital pricing instruments should be regulated in order to provide fair competition.

The first approach suggests not to start developing additional normative instruments and observe, since the exact influence of algorithmic pricing on the state of competition is not fully studied yet.

The second approach implies the regulation of introducing the pricing algorithms ex ante just like commercialization of new medicine: any new pricing algorithm should be tested by a regulating authority in order to determine whether it can potentially provoke creation of a cartel (in case it is to be banned by the regulator) or cannot (in this case it is sanctioned).

The introduction of such preliminary regulation is supported in research of Ezrachi and Stucke who note the possibility of creating a "digital sandbox" where pricing algorithms could be modeled and studied, creating their regulation as a result of such empirical studies [5].

Finally, the third approach lies in ex post regulation, as it usually happens in competition law; however, it implies using new legal standards. In particular this approach requires reassessment of the disputable question of the tacit collusion ban.

A fourth approach can be found in literature, it implies a total ban of algorithmic pricing; however, in our view, such measures are unreasonable. Evidently, using digital instruments in competition law benefits the markets in pricing since the pricing becomes more economically effective.

We agree with Calvano and Calzolari who note that legal regulation of applying the instruments of algorithmic pricing confronts insufficient elaboration of their essence and peculiarities of their application. In particular, features of collusion of pricing algorithms can depend on what other algorithms they interact with. Let us assume that an algorithm A was approved based on the proof that it does not tend to collude with the existing algorithms B, C and D. Suppose that a new algorithm E tends to collude with A but not with $\mathrm{B}, \mathrm{C}$ and $\mathrm{D}$. Which algorithm should be banned? $\mathrm{E}$ is better than $\mathrm{A}$, so on grounds of effectiveness $\mathrm{E}$ must be approved and A must be banned. However, A was approved from the beginning, so banning it at a later stage may turn out to be quite costly [7].

Nevertheless, extremes in setting regulating measures are evidently ineffective as well. Practicing specialists must review proactive approaches to providing consumers and authorities with possibilities to check algorithms and using their personal information on the spot in order to enable the assessment based on influence [15]. Such algorithmic audit can be accompanied by a system of algorithmic certification, as well as with certification of developers based on ethics codes [20].

Describing what approaches to regulating the application of pricing algorithms are to be put into practice, M. Gal gives the following interesting example: "A commissioner of the Federal State Commission Maureen Ohlhausen has suggested a simple test that records a lot of these simple cases: if the word "algorithm" could be replaced with a phrase "a guy called Bob" then one can work with algorithms just like with traditional agreements". In this case it comes to a situation when there is a cartel collusion between entities and algorithms just serve as instruments for realization of such agreement. However, another option is possible, when algorithms serve as self-learning programs that under certain conditions regulate the prices by themselves based on each other's figures, interacting in order to adjust the price. It is noted that right holders using algorithms in such situations can be viewed as a cartel, except for the cases when such use causes "significant compensatory profits" for consumers [21].

However, there is still no definitive answer to the question of how to qualify coordination of prices when there is no agreement on such coordination. In other words, when several entities independently develop pricing algorithms that are based on the principles of autonomous functioning; the price increases as a result of their application.

The mere use of algorithms does not prevent the application of legal liability to their developers or users. As a competition European Commissioner has stated, "entities should be accountable for the consequences of algorithms they had chosen to use". In order for the legal liability to appear, the developer or the user should know about the price effects being created. This could be illustrated with an example of European Eturas [22]; 30 Lithuanian travel agencies have participated using the same online booking system. The system operator has programmed the algorithm is such a way so that the agencies would not be able to offer more than 3\% discounts and has notified the agencies about this restriction through the inner messaging system. The agencies have used the algorithm. The question was whether these events imply that there was an agreement between the agencies on changing the algorithm and reducing competition. The European court has admitted the awareness about the changes in the algorithm to be a necessary condition for identifying a cartel. Underestimating the possible effects of algorithms under certain circumstances can be sufficient for proving awareness. What kind of awareness is required in cases when the algorithm designed for autonomous identification of decision taking parameters contributes to collusion [21]. In literature this phenomenon is called "cartel of the machines" [8].

\section{Conclusion}

In our opinion, the following approach is logical; since any software even while performing defined, already set functions, does not act upon its will and is controlled by its creator and/or right holder, the actions of "cartels of the machines" concerning pricing violating competition are the direct consequence of behavior of such creators (right holders). As a result, it is logical that for any actions of the machines, even relatively autonomous and based on autonomous calculations of the algorithms, the program owners should be held accountable (since even inaction (intended non-interference to the activity of the program) can serve as indirect evidence of coordinated anti-competition practice). 


\section{References}

1. K. Doi, OECD Discussion on Digital Diffusion Problems, $11 \quad$ (2018), $\quad$ URL: https://fas.gov.ru/pages/internationalpartnership/oesr/oesr-gvx-rczk/informaczionnyijbyulleten-oesr-gvx-rczk/ (date of access: 01.12 .2020 )

2. A. Tsarikovsky, E. Voynikanis, A. Ivanov, Antitrust in the Digital Age: How to Protect Competition in the Context of Globalization and the Fourth Industrial Revolution (National Research University Higher School of Economics, 2019) https://doi.org/10.17323/978-5-7598-1984-4

3. P. Honoré, R. Verzeni, Italian Antitrust Review, 4 (2) (2018) https://doi.org/10.12870/iar-12853

4. S. Hutchinson, Law. Journal of the Higher School of Economics 1, 216-245 (2017) https://doi.org/10.17323/2072-8166.2017.1.216.245

5. A. Ezrachi, M.E. Stucke, SSRN Electronic Journal (2015) https://doi.org/10.2139/ssrn.2591874

6. A. Ezrachi, SSRN Electronic Journal (2018) https://doi.org/10.2139/ssrn.3191766

7. E. Calvano, G. Calzolari, V. Denicolò, S. Pastorello, Review of Industrial Organization 55 (1), $155-171$

(2019) https://doi.org/10.1007/s11151-019-09689-3

8. A. Heinemann, A. Gebicka, Journal of European Competition Law \& Practice 7 (7), 431-441 (2016) https://doi.org/10.1093/jeclap/lpw036

9. A.V. Dotsenko, A.Y. Ivanov, Law 3, 31-45 (2016)

10. $\mathrm{AD} / 74808-\mathrm{DSP} / 20$ (2020), URL: https://br.fas.gov.ru/ca/upravlenie-regulirovaniyasvyazi-i-informatsionnyh-tehnologiy/b70e9d96$8 \mathrm{~d} 39-46 \mathrm{f} 5-9 \mathrm{~d} 7 \mathrm{~d}-$ 342da95b354b/?query=App\%20Store (date of access: 01.12.2020)

11. Competition Issues in the Digital Economy (TD/B/C.I/CLP/54) (2019), URL: https://undocs.org/ru/TD/B/C.I/CLP/54 (date of access: 01.12.2020)

12. IA/49910/20, URL: https://br.fas.gov.ru/ca/upravlenie-regulirovaniyasvyazi-i-informatsionnyh-tehnologiy/2b16e00b8fd3-4df7-a551-a46d814248ee/ (date of access: $01.12 .2020)$

13. T. Wu, The Master Switch: The Rise and Fall of Information Empires (Vintage Books, 2011)

14. Great Encyclopedic Dictionary 1 Soviet encyclopedia (Algorithm, 1979)

15. P. Seele, C. Dierksmeier, R. Hofstetter, M.D. Schultz, Journal of Business Ethics (2019) https://doi.org/10.1007/s10551-019-04371-w

16. Algorithms and Collusion: Competition Policy in the Digital Age, URL: www.oecd.org/competition/algorithms-collusioncompetition-policy-in-the-digital-age.htm (date of access: 01.12.2020)
17. Former E-Commerce Executive Charged with Price Fixing in the Antitrust Division's First Online Marketplace (2015), URL: https://www.justice.gov/opa/pr/former-ecommerce-executive-charged-price-fixing-antitrustdivisions-first-online-marketplace (date of access: 01.12.2020)

18. S. Borenstein, Rapid Price Communication and Coordination: The Airline Tariff Publishing Case 19 (1994)

19. 4-14.32-340/00-22-18 (2018), URL: https://fas.gov.ru/documents/ats-46961-18 (date of access: 01.12.2020)

20. J. Beranger, The Algorithmic Code of Ethics: Ethics at the Bedside of the Digital Revolution. Wiley-ISTE (2018)

21. M.S. Gal, Illegal pricing algorithms. Communications of the ACM 62 (1), 18-20 (2018) https://doi.org/10.1145/3292515

22. C-74/14 (2016), URL: http://curia.europa.eu/juris/document/document.jsf? text $=\&$ docid $=173680 \&$ pageIndex $=0 \&$ doclang $=\mathrm{EN}$ $\&$ mode $=1$ st \&dir $=\&$ occ $=$ first\&part $=1 \&$ cid $=523288$ (date of access: 01.12.2020) 